\title{
What Are the Other Energy Functions of the Heart That We Need To Know Besides It Being A Blood Pump?
}

\section{Huang Wei Ling}

Infectious Diseases, General Practice, Nutrition, Acupuncture and Pain Management. Medical Acupuncture and Pain Management Clinic, Franca, São Paulo, Brazil

Corresponding Author: Huang Wei Ling, Rua Homero Pacheco Alves, 1929, Franca, São Paulo, Brazil. $14400-010$.

Received Date: August 27, 2021; Accepted Date: September 15, 2021; Published Date: September 20, 2021

Citation: Huang Wei Ling. (2021) What Are the Other Energy Functions of the Heart That We Need To Know Besides It Being A Blood Pump?. J. Clinical Cardiology and Cardiovascular Interventions, 4(15); Doi:10.31579/2641-0419/218

Copyright: ( 2021 Huang Wei Ling, This is an open-access article distributed under the terms of the Creative Commons Attribution License, which permits unrestricted use, distribution, and reproduction in any medium, provided the original author and source are credited.

\section{Abstract \\ This article will be based on the commandments of Hippocrates ( 460 bce -375 bce), father of medicine, who said that we must study the oldest medicines before the current medicine practiced today. \\ Keywords: heart; energy; traditional chinese medicine; chakras; homeopthy}

\section{Introduction:}

This article will be based on the commandments of Hippocrates (460 bce -375 bce), father of medicine, who said that we must study the oldest medicines before the current medicine practiced today. [1]

Hippocrates was the author of the theory of humors, in which he said that for the human being to be healthy, must have balances of the four humors, which are Black bile, Yellow bile, Phlegm and Blood. [1]

For this reason, the author will use concepts in traditional Chinese medicine to explain, which are the other energy functions of the Heart, besides being a Blood pumper? [2]

According to traditional Chinese medicine, everything that exists in our universe is made by energy and it is characterized by the balance of Yin and Yang energies. Just as we have day and night, sun and moon, summer and winter, woman and man, all the internal organs of the human being also have Yin and Yang energies. [3, 4]

Yin energy is characterizing the matter part and Yang energy from the energy of the heart's action. $[4,5]$

The Heart represents one of the five massive organs of traditional Chinese medicine and its functions, in addition to pumping Blood to nourish and deliver oxygen to the body's cells and systems (that have been very well discussed throughout a literature of Western medicine), is also composed of a part of energy, something that is not studied by Western medicine, as it was considered unscientific after the implementation of the Flexner report in 1910. And since then, it has not been studied and its understanding was not deepened by medical schools around the world. [6] According to the article written by O'Brien (2010) entitled Alternative

Perspectives: How Chinese Medicine Understands Hypercholesterolemia, there are many collaterals and meridians that pass through the Heart (Kidney, Spleen and Small intestine) and and for this reason the dysfunction of the Heart may affect other organs. The function of Heart is commander of the Blood and dominates vessels and Blood. It is the major organ responsible for Blood circulation. According to this article, the Heart has another function that is House of Shen. Shen is the same as vitality and spirit and it is the exterior manifestation of physiological functioning (mental and consciousness and including perception, thinking and memory). [7]

According to the The Yellow Emperor's Classic of Internal Medicine: Basic Questions, wrote by Huang Di Nei Jing Su Wen, the Heart represents the consciousness of the individual's being, and it is responsible for spiritual transformation, intelligence and wisdom. It is connected to the tongue by internal meridians and the incoherent speech can be sign of pathology of the Heart. [8]

For each internal massive organ (Liver, Heart, Spleen, Lung and Kidney), they command the functioning of one of the five external sense organs (vision, communication, taste, smell, and hearing respectively). [4] 
In the case of the Heart, it commands the speech and communication and the sleep process of individuals. [2]

These functions that are little known and studied by Western medicine, because normally Western medicine treats speech problems as a localized problem, doing local exercises, but does not treat the cause, which is the imbalance of Heart energy, that is leading to speech disorders. [2]

In the article written by Huang (2020) entitled What Is the Cause of Language Impairment in Traditional Chinese Medicine and How Can We Treat It?, she is presenting one case report of 5-years-old male patient with history of language impairment and was being treated by Western medicine's tools with no improvement of his condition. The author did the chakras' energy measurement and showed that all his chakras' energy centers from one to six was in a very low energy pattern (rated one out eight) with the exception of the seventh chakra', that was normal, rated in eight. The Heart corresponds in this situation, to the third chakra (that was also impaired) and the treatment using Chinese dietary counseling, auricular acupuncture with apex ear bloodletting, and replenishing the chakras' energy centers with highly diluted medications according to the theory Constitutional Homeopathy of the Five Elements Based on Traditional Chinese Medicine and using crystal based medications, were important for the improvement of the speech disorders condition of that patient and not only treating the symptoms. [2]

According to the authors' experience, people who speak little, or do not speak, or who stutter, also have lack of the Heart's energy. [2]

The author was treating recently a patient undergoing treatment for stroke, after using hormone to treat abnormal uterine hemorrhage. This patient had compromised her right hemi body, leading to impairment of the movement. In addition, it was also compromised her speech functions. Analyzing her chakras' energy centers through radiesthesia procedure, the author noted that the patient had a deficiency in the energy of the Heart, in addition to other energy deficiencies in other massive organs. This finding of complete energy deficiency is a very common finding in patients who have history of stroke, reported in the article written by Huang (2021) entitled What We Need to Know When the Patient has a Stroke with or without COVID-19? [9]

According to Western medicine reasoning, there is the tendency to say that the strokes' patient's speech problem was due to a stroke, but according to the clinical experience by the author, dealing with the deficiencies of all the energy of the internal organs, including the Heart (or third chakra), replenishing the energy with highly diluted medications according to the theory Constitutional Homeopathy of the Five Elements Based on Traditional Chinese Medicine, was enough to help the patient to speak more normally, because before the treatment the patient could not express the words, what she thought to say, she could not express and speak. [9]

This is very common in people who are anxious, shy, who usually do not speak, but the process of talking erase needs energy and what the author realizes, that patients do not speak and do not talk due to lack of Heart energy and after treatment, people start talking, even in children, and starts to communicating and expressing their feelings, as it was difficult to happen when Heart energy was deficient and it was not treated accordingly. [2, 9]

Another very important aspect of Heart energy is about the sleeping process. [10]

According to traditional Chinese medicine, patients who have insomnia usually have energy deficiency in the Heart but other energy alterations can also leading to insomnia, such as Blood energy deficiency (caused by energy deficiency in the fifth chakra) and Kidney deficiency (second chakra) or Heat in the Gallbladder and Liver (first chakra). [10]

Depending on what time the individual is waking up, we will know which internal organ is affected leading to insomnia. [11]

For example, if insomnia is caused by Gallbladder imbalance, the individual will wake up between 11 and 1 AM. If the individual wakes up between 3 and 5 AM, it is due to the involvement of the Lung meridian. And if the patient is eating his dinner very late, the food will stagnate in the Stomach and can cause insomnia. That is why, the author always advises the patients to eat the dinner until 6 PM, as eating after this time, can cause stagnation of food in the gastrointestinal tract, as the gastrointestinal tract stops working at 6 PM. [11]

It is common after the treatment of replenishment of this lack of energy in the chakras' energy centers, using highly diluted medications such as homeopathy medications according to the theory Constitutional Homeopathy of the Five Elements Based on Traditional Chinese Medicine, patients reported to go back to sleep deeply and start to sleep at night. Their sleep process always returned to normal condition where they usually say that they began to sleep very deeply and start to do not awake in the middle of the night and wake up with energy and very restored to begin the day with more energy. [10, 12]

In an article written by Huang (2021) entitled Energy Alterations and Chakras' Energy Deficiencies and Propensity to SARS-CoV-2 Infection, the author studied the energy of her 1000 patients' chakras energy centers during 2015 and 2020, and she concluded that $97 \%$ of patients had no energy in the Heart. [13]

More than $90 \%$ of the analyzed patients had no energy in any of the five massive internal organs, such as the Liver, Heart, Spleen, Lung and Kidney. Contrary to what Western medicine thinks, all internal organs are 
interconnected and one organ is responsible for sending energy to the other organ. This principle has already been well described in the Generation cycle and in the Control cycle of the Five Elements Theory, in traditional Chinese medicine, which has been existed for around 5,000 years. [4]

Due to these interrelationships, there are processes that manifest in the Heart but being the cause of the problem in another organ. For example, there are patients who have tachycardia, and that they are usually evaluated locally by performing electrocardiogram tests of the Heart and other tests. However, this symptom is very common in patients who have internal Heat formation, such as in patients who have panic syndrome, in which the energy imbalance is in the Gallbladder, which is an organ that is coupled to the Liver and when there is excess energy from the Liver and from the Gallbladder, this energy is transmitted to the Heart, giving symptoms of tachycardia. This study was presented by the author in the Webinar on Cardiology \& Atherosclerosis, that was held on January 28th, 2021, in the study entitled Energies Imbalances and Chakras' Energies Deficiencies as One of Cause of Tachycardia [14, 15]

These patients are treated in Western medicine with drugs to reduce Heart rate, such as beta blockers, but they are not treating the cause of the problem, that is generated by imbalance of Gallbladder energy, with internal Heat build-up from dietary errors, emotion such as anger, and excess of medications, etc. [15]

The process of lack of energy in the Heart can lead to dyspnea symptoms; described in the article written by Huang (2021) entitled Are the Pulmonary Manifestations in COVID-19 Really Caused by the Virus? In this article, the author is describing that when the difficulty is due to breathing air, this is caused by the lack of energy in the Kidney (second chakra) and the dyspnea manifestations of COVID-19 patients could be caused by this lack of energy and not caused by the virus itself. When the difficulty of breathing is in the process of exhaling air, this may be caused by a deficiency in the Heart's energy. These affirmations were written in another article by Huang (2021) entitled Chakras' Energies Deficiencies as the Cause of Dyspnea Post COVID-19 Treatment. [16, 17]

The imbalance of the Heart's energy can lead to sleepwalking symptoms, and patients who have this kind of problem, when they are treating the Heart energy disharmony, they go back to their normal sleeping process, without being sleepwalkers. In the article written by Aung et al. (2013), entitled Traditional Chinese Medicine as a Basis for Treating Psychiatric Disorders: A Review of Theory with Illustrative Cases, they are saying that somnambulism is related to the deficiency in the congenital Kidney essence and leading to the Shen impairment of the Heart. [18]
Another disease treated by Western medicine and it is related to energy of the Heart is the schizophrenia. According to traditional Chinese medicine, schizophrenia can come from excess of the five minds and seven effects. And the excessive fear, anger, fright and thoughts can cause disturbances of the functioning of the viscera and bowels and loss of balance between Yin and Yang energy. All these alterations can cause depression of $Q i$ and cause Blood stasis and other changes that can cause obstruction of the Heart orifices and cause a chaos in the spirit and resulting in psychological abnormalities. [18]

The treatment replenishing these energy is very common in almost all patients nowadays (as the author showed in the article she wrote entitled Energy Alterations and Chakras' Energy Deficiencies and Propensity to SARS-CoV-2 Infection), including babies, children, adults and the elderly, through the use of highly diluted medications such as homeopathies, according to the theory the author created entitled Constitutional Homeopathy of the Five Elements based on Traditional Chinese medicine and using crystal-based medications. In this article, the author is saying that $90 \%$ of her patients studied between 2015 and 2020, have chakras' energy centers deficient in energy, including the Heart's energy and for this reason, it is important to treat these energy deficiencies because energy means our immunity. [12, 13]

The author recommends the use of homeopathies, currently as the medicine of choice to treat all kinds of diseases nowadays, due to the changing in the energy pattern of the entire world population, generated by the electromagnetic waves influences of the globalized modernization of telecommunication, very well described in the article published by uang (2021) entitled Energy Alterations and Chakras' Energy Deficiencies and Propensity to SARS-CoV-2 Infection. [13]

Since 2015, the author has been studying homeopathy and since she started her course in Brazil, she has written a new theory that links the homeopathy created by Hahnemann (1755-1843), with thoughts from traditional Chinese medicine, that exists for more than 5.000 years. [12]

This was necessary, despite homeopathy medications being a very effective method of treatment, it is still not very well understood, which mechanism of action it acts. [12]

In the book Bioenergetics Medicines East and West: Acupuncture and Homeopathy, written by Manning and Vanrenen (1993), they are saying that homeopathy works as bioenergy, similar to the mechanism of action of acupuncture. [19]

According to Hippocrates, natural forces that we have within us are the greatest healers of the disease. Therefore, using homeopathies, they would work as if they were the energy of the organs (that it is in the lowest level of energy nowadays), so the internal organs are better able to carry 
out their usual activities, to maintain all the external sensorial organs functioning and producing the internal energy's to keep the health of the patients. [1, 12]

As already described in many ancient writings by the author, the Heart energy commands the flow of Blood within the blood vessel, and it is represented by the third chakra. Blood is an energy produced by Spleenpancreas meridian (fifth chakra). Yin and Yang energy are produced in the Kidney (second chakra) and $Q i$ energy is distributed by the energy of the Liver and Lung (first and fourth chakras respectively). [4]

The importance of balancing the internal energies was presented by the author at the Acupuncture Research Congress that was held at Harvard Medical School, in Boston, in 2015, where the author presented the theory balancing these four energies, and resulting in the treatment of all the patient's physical and emotional conditions at the same time. If the physician treats the root, it deals with the cause of all problems, that are represented at the root of the tree (of the tree metaphor) and she also explains the meaning of this metaphor in all articles published by her. [20] This theory was also used in the article written by Huang (2021) entitled Chakras' Energies Deficiencies as the Main Cause of Myocardial Infarction without Arterial Obstruction and in another article written by Huang (2020) The Importance of Correcting Chakras Energy Centers Alterations to Prevent Pacemaker Indication, among many other articles in the cardiology field. [3, 21]

Therefore, the author is writing this editorial to know that we need to understand the totality, to understand the whole human being and that the human being is made of energy and matter and if we understand only part of it (only matter), we will not understand the totality and in this way, many diseases and pathologies could be prevented, if the physician had the opportunity to learn and develop to their full potential, as currently the understanding of the totality of the human being was cut in half, after the implementation of norms in the past, such as the implementation of the Flexner report, supported by the Rockefeller and by Carnegie foundation.

Therefore, the Heart not only pumps Blood, there are other functions it performs that are part of the human being and it is very important for the doctor to understand its entirety, and not just the parts, because the human being is not just a Heart or just a Lung or the parts, but an integral being that has the physical, emotional and spiritual parts and that must be integrated and not separated, as they are treated by scientific medicine today. [22]

\section{References}

1. Craik E. "The "Hippocratic" Corpus: Content and Context". Routledge (2014): 344.
2. Huang WL. "What is the Cause of Language Impairment in Traditional Chinese Medicine and how can we Treat it?" Journal of Clinical Case Reports and Trials 2.2 (2019): 14-22.

3. Huang Wei Ling, Chakras' Energies Deficiencies as the Main Cause of Myocardial Infarction without Arterial Obstruction. Online Journal of Cardiology Research \& Reports. 2021; 4(5).

4. Huang Wei Ling, Why Are Diabetic Patients Still Having Hyperglycemia Despite Diet Regulation, Antiglycemic Medication and Insulin? Int J Diabetes Metab Disord. 2019; 4(2):1-14.

5. Huang Wei Ling, Why Do Patients Still Catch Hospital Infections Despite the Practice of Infection Prevention and Control Programs? Acta Scientific Microbiol. 2018; 1(4):3443.

6. Xie-Ning Wu. Current concept of Spleen-Stomach theory and Spleen deficiency syndrome in TCM. World J Gastroenterol. 1998 Feb 15; 4(1): 2-6. Published online 1998 Feb 15. doi: 10.3748/wjg.v4.i1.2

7. Kylie A O'Brien. Alternative perspectives: how chinese medicine understands hypercholesterolemia. Cholesterol. 2010;2010:723289. doi: 10.1155/2010/723289. Epub 2010 Aug 11.

8. Ni M. "Yellow Emperor's Classic of Medicine: The Essential Text of Chinese Health and Healing". First. Shambhala, Boston and London (1995).

9. Huang Wei Ling. "What We Need to Know When the Patient has a Stroke with or without COVID-19?". Acta Scientific Neurology 4.8 (2021): 01-05.

10. Huang W L. Why Insomnia Patients Do Not Sleep Even When Taking Sleep Inducers Medications?. Open Access J Neurol Neurosurg 2021; 15(4): 555916. DOI: 10.19080/OAJNN.2021.15.555916

11. Huang Wei Ling, Auricular Acupuncture and Chinese Dietary Counseling in The Treatment of Insomnia. Archives of Neurology and Neuro Disorders. 2020; 3(1):1-11.

12. Huang Wei Ling, Constitutional Homeopathy of Five Elements Based on Traditional Chinese Medicine. Acta Scientific Medical Sciences. 2020; 4(7):57-69.

13. Huang Wei Ling. "Energy Alterations and Chakras' Energy Deficiencies and Propensity to SARS-CoV-2 Infection". Acta Scientific Microbiology 4.4 (2021): 167-196.

14. Webinar on Cardiology \& Atherosclerosis. January 28th, 2021. Retrieved 08/31/2021.

15. Huang Wei Ling, Energy Disturbances in Panic Syndrome and How Can We Teat It in Adolescence? J Neurol Exp Neural. 2020; 3(1):139.

16. Huang Wei Ling, Chakras' Energies Deficiencies as the Cause of Dyspnea Post COVID-19 Treatment. Journal of Infectious Diseases \& Case Reports. 2021;2(1):1-9.

17. Huang Wei Ling (2021) Are The Pulmonary Manifestations in COVID-19 Really Caused by the Virus?. Journal of Pulmonology Research \& Reports. SRC/JPRR-116.

18. Aung S, et al. Traditional Chinese Medicine as a Basis for Treating Psychiatric Disorders: A Review of Theory with Illustrative Cases. Med Acupunct. 2013 Dec 1; 25(6): 398-406. doi: 10.1089/acu.2013.1007

19. Manning, Clark; Vanrenen, Louis. Bioenergetic Medicines East and West: Acupuncture and Homeopathy. (February 9, 1993) Paperback.

20. Huang Wei Ling, The Importance of Correcting Energy Imbalances and Chakras Energy Deficiencies in the Treatment of Patients with Glaucoma. Clin Res Ophthalmol. 2019; 2(2):19. 
21. Huang Wei Ling, The Importance of Correcting Chakras Energy Centers Alterations to Prevent Pacemaker Indication. Acta Scientific Medical Sciences. 2020; 4(6):102-109.
22. Huang Wei Ling. "What Flexner Report did to Our Medicine After 100 Years of Implantation?". Acta Scientific Gastrointestinal Disorders 4.8 (2021): 01-04.
Ready to submit your research? Choose Auctores and benefit from:

* fast, convenient online submission

* rigorous peer review by experienced research in your field

* rapid publication on acceptance

* authors retain copyrights

* unique DOI for all articles

* immediate, unrestricted online access

At Auctores, research is always in progress.

Learn more www.auctoresonline.org/journals/clinical-cardiology-andcardiovascular-interventions

DOI: $10.31579 / 2641-0419 / 218$ 